\title{
Why is Hippocampal CA1 Especially Vulnerable to Ischemia?
}

\author{
Hanbai Liang ${ }^{1}$, Shota Kurimoto ${ }^{1}$, Kosuke R Shima ${ }^{2}$, Hiroki Shimizu ${ }^{2}$, Tsuguhito Ota ${ }^{2}$, Yoshio \\ Minabe $^{3}$ and Tetsumori Yamashima ${ }^{1,3 *}$ \\ ${ }^{1}$ Department of Restorative Neurosurgery and Psychiatry \\ ${ }^{2}$ Department of Cell Metabolism and Nutrition, Brain/Liver Interface Medicine Research Center \\ ${ }^{3}$ Department of Psychiatry and Neurobiology, Kanazawa University Graduate School of Medical Science. \\ 13-1 Takara-machi, 920-8640, Kanazawa, Ishikawa, Japan
}

Received: 09 November, 2016; Accepted: 30 November, 2016; Published: 03 December, 2016

*Corresponding author: Tetsumori Yamashima, Department of Restorative Neurosurgery and Psychiatry, Kanazawa University Graduate School of Medical Science, Kanazawa, Japan, Tel: +81(90)2129-1429, Fax: +81(76)247-1338, E-mail: yamashima215@gmail.com

\begin{abstract}
Since the formulation of 'calpain-cathepsin hypythesis' in 1998, calpain-mediated lysosomal rupture has been accepted to explain the mechanism of neuronal death. As Hsp70.1 contributes to the chaperone function of aged/damaged proteins and membrane stabilization of lysosomes, its depletion can induce neurodegeneration via autophagy failure and lysosomal destabilization. The cleavage assay in vitro previously showed that Hsp70.1 is a substrate of activated $\mu$-calpain, especially after its carbonylation by the lipid peroxidation product hydroxynonenal (HNE). The hippocampal CA1 neurons are known to be especially vulnerable to the ischemic insult, but the underlying mechanism still remains incompletely elucidated. Here, using various primate brain tissues including thalamus, putamen, medulla oblongata, and CA1, calpain-mediated in-vitro cleavage of Hsp70.1 which eventually leads to the lysosomal rupture was analysed after treatment with or without HNE. In all tissues studied Hsp70.1 cleavage from size $70 \mathrm{kDa}$ to $30 \mathrm{kDa}$ occurred only in the presence of activated $\mu$-calpain, and the increasing HNE treatment caused a stepwise escalation in cleavage. However, in the absence of calpain activation, the protein carbonylation alone, even by the larger HNE doses, failed to cause Hsp70.1 cleavage. Although the pathogenic synergism between calpain activation and Hsp70.1 carbonylation works in concert, $\mu$-calpain is considered to be the principal factor whereas HNE alone could not mediate Hsp70.1 protein cleavage. With the aid of HNE, calpain activation would facilitate lysosomal destabilization by cleaving carobonylated Hsp70.1. Among the 4 brain tissues studied, the CA1 tissue intriguingly showed the minimum Hsp70.1 cleavage. Accordingly, the specific vulnerability of CA1 neurons in the living brain can be explained by their excessive and/or long-standing calpain activation due to the remarkable $\mathrm{Ca}^{2+}$ mobilization potential.
\end{abstract}

Keywords: Neuronal Death; Lysosome; Hsp70.1; Carbonylation; Calpain-Cathepsin Hypothesis

\section{Introduction}

Since 1998 when the 'calpain-cathepsin hypothesis' was formulated by Yamashima and his associates [1], it became gradually accepted as a molecular mechanism of necrotic neuronal death [2]. The core of this hypothesis is calpainmediated lysosomal destabilization/rupture and the resultant release of lysosomal cathepsin enzymes. However, the in-vivo substrate of calpain for inducing lysosomal destabilization had long remained unknown. A molecular chaperone Hsp70.1, a major human Hsp70, also called Hsp72 or HSPA1, is recently known to stabilize lysosomal membrane by recycling damaged proteins and protect cells from oxidative stresses [3,4]. Hsp70.1 is crucial for cell death, because Hsp70.1 gene knockout-mice showed exacerbation infarction size after focal cerebral ischemia [5]. In contrast, enhanced Hsp70 expression in transgenic mice protected the brain and heart from ischemia by an unknown mechanism [6-9].

In both the rodent [10] and primate [11,12] experimental paradigms, Hsp70.1 is susceptible to the oxidative stressinduced modification especially by a lipid peroxidation product - hydroxynonenal (HNE). In a rat model of chronic alcoholinduced oxidative stress, Carbone, et al. [13] showed that Hsp72, the inducible variant of Hsp70, treated with 10 and $100 \mu \mathrm{M}$ HNE caused adduct formation at Cys267 in the ATPase domain of the chaperone by the mass sprectrometrical analysis. Recently, the author's group has suggested that oxidative modification of Hsp70.1 occurs early in the pathogenesis of neuronal death in the postischemic monkey hippocampus. In response to HNE being generated by the oxidative stress, a specific oxidative injury 'carbonylation' occurred at the key site Arg469 of Hsp70.1, which coincides well with the carbonyl increase [11]. Furthermore, analyses of the postischemic hippocampal tissues [14] and the glaucoma-suffered retina [15] in primates showed the same result that Hsp70.1, especially after HNE-mediated carbonylation, is susceptible to cleavage by activated $\mu$-calpain.

Because of its chemical reactivity, HNE can exert pleiotropic effects particularly in cell death. For example, after the ischemia/ reperfusion sequence in myocardial infarction, accumulated Reactive Oxygen Species (ROS) promote generation of HNE, which disrupts the actin cytoskeleton, alters $\mathrm{Ca}^{2+}$ homeostasis, and triggers cardiomyocyte cell death [16]. HNE induces signaling for apoptosis via both the Fas-mediated extrinsic and 
the p53-mediated intrinsic pathways $[17,18]$. So, HNE can trigger the pancreatic $\beta$ cell apoptosis, induce glucose intolerance and the development of diabetes [19]. As HNE impairs $\mathrm{Na}^{+} / \mathrm{Ca}^{2+}$ pumps and glucose and glutamate transporters by modifying membranes, the resultant ionic and energetic disturbances may cause neuronal cell death $[20,21]$. However, the detailed mechanisms of calpain and HNE synergy as well as contribution of each player for the cell death still remain incompletely elucidated.

The present study aimed at elucidating why the hippocampal CA1 is especially vulnerable to the ischemic insult among the various brain regions by focusing cysteine protease 'calpain' and lysososomal stabilizer 'Hsp70.1'. Here, using four representative brain portions of the non-human primates, the calpain-mediated Hsp70.1 cleavage was compared in-vitro to elucidate (1) [22] how the calpain and HNE synergy affects, (2) [13] whether calpain or HNE alone can induce the Hsp70.1 cleavage, and (3) [17] which is the principal factor. Although the data are artificial, they are helpful for understanding the diverse function of Hsp70.1 protein under the stress condition.

\section{Materials and methods}

Using the non-ischemic monkey (Macaca fuscata) brain tissues, Western blotting was done to analyse Hsp70.1 cleavage as reported previously [23]. All experimental procedures were performed in strict adherence with the guidelines of the Animal Care and Ethics Committee of Kanazawa University and the NIH Guide for the care and Use of Laboratory Animals. Four young monkeys with a body weight of $6-10 \mathrm{~kg}$ were bred in airconditioned cages and allowed free daily access to food and water. Under GOF general anesthesia, the monkeys were sacrificed for the normal brain tissue sampling. We aimed to examine whether activated $\mu$-calpain (calpain-1) can cleave Hsp70.1 being involved in the homogenate tissues of non-ischemic thalamus, putamen, medulla oblongata, and CA1 in vitro, by adding purified $\mu$-calpain (Calbiochem, La Jolla, CA) plus $\mathrm{Ca}^{2+}$ mixed with or without HNE (Calbiochem, La Jolla, CA).

For the in-vitro $\mu$-calpain activation, various concentrations $(0,1,3 \mathrm{mM})$ of $\mathrm{CaCl}_{2}$ (Wako Pure Chemical, Osaka, Japan) were added with 0.5 units (U) $\mu$-calpain to the homogenate tissue samples $(20$ or $5 \mu \mathrm{g})$ and the recombinant Hsp70.1 protein (200 ng). Calpain buffer comprised of $1 \mathrm{M}$ Tris pH7.2, $100 \mathrm{mM}$ DTT, $10 \mathrm{mM}$ EDTA, and $26 \mathrm{mM}$ EGTA. The $\mu$-calpain activation was stopped by adding $100 \mu \mathrm{M}$ EDTA and EGTA (Dojindo Laboratories, Kumamoto, Japan).

Subsequently, using various concentrations of $\operatorname{HNE}(0,1,2$ $\mathrm{mM}$ ), it was studied whether oxidative stress-induced Hsp70.1 carbonylation can promote its cleavage by activated $\mu$-calpain. Furthermore, the homogenate brain tissues were incubated for various times $(0,1,5,10,30,60,120 \mathrm{~m})$ in $2 \mathrm{mM}$ HNE with activated $\mu$-calpain that was made from $0.5 \mathrm{U} \mu$-calpain after incubation in $3 \mathrm{mM} \mathrm{CaCl}_{2}$. Since the configuration of the Hsp70.1 cleaved bands was sometimes not distinct because of the presence of consecutive bands around $30 \mathrm{kDa}$ (for example, Figures 2, 3 and 6), the densitometolytic analysis of the band intensity was not done.
The protein samples from the homogenate brain tissues after given incubation were separated by $15 \%$ SDS-PAGE gel (Biocraft, SDG-571) and transferred on the PVDF membrane (ATTO, Tokyo, Japan). Primary antibody was purified mouse anti-human HSP70 that recognizes amino acid 429-640 residue (at a dilution of 1:6,000, BD Transduction Laboratories, 610607, San Jose, California, USA), while the secondary antibody was horseradish peroxidase-conjugated goat anti-mouse IgG (at a dilution of 1:10,000, Santa Cruz Biotechnology, SC-3697, Santa Cruz, USA). The recombinant Hsp70.1 protein (recombinant human Hsp70/ Hsp72, Enzo Life Science, ADI-NSP-555-D) was utilized as a positive control.

\section{Results}

First, to determine the optimal amount of purified $\mu$-calpain under $3 \mathrm{mM} \mathrm{Ca}^{2+}$ concentration in the absence of HNE, in-vitro cleavage of Hsp70.1 was analyzed using 0.2, 0.5 and 1.0 units (U) of $\mu$-calpain to the recombinant Hsp70.1 protein (200 ng) and the thalamus tissue $(20 \mu \mathrm{g})$. Hsp70.1 cleavage into the 30 $\mathrm{kDa}$ fragment occurred by activated $\mu$-calpain alone. Although the calpain-mediated proteolysis was negligible without calpain activation in both the recombinant and the tissue, it increased dose-dependently after calpain treatment (Figure 1). There were about $60 \mathrm{kDa}$ protein bands in the recombinant Hsp70.1 cleavage panel, but not in the thalamus tissue (Figure 1). This is presumably because 2D structure recombinant protein was prone to calpain cleavage, compared to 3D structure Hsp70.1 protein in the thalamus tissue. Since $\mu$-calpain concentration of $0.5 \mathrm{U}$ appeared to be sufficient in both the recombinant and the tissue for cleaving Hsp70.1 into $30 \mathrm{kDa}$ fragment, $0.5 \mathrm{U} \mu$-calpain was utilized in the following experiments.

Next, the optimal $\mathrm{Ca}^{2+}$ concentration necessary for $0.5 \mathrm{U}$ $\mu$-calpain activation was to determined. In all HNE concentrations of $0.5,1$ and $2 \mathrm{mM}, 1 \mathrm{mM} \mathrm{Ca}^{2+}$ failed to cleave the recombinant Hsp70.1 protein $\left(200 \mathrm{ng}\right.$ )(data not shown), but $3 \mathrm{mM} \mathrm{Ca}^{2+}$

\section{Recomb Hsp70.1 Thalamus \\ Calpain

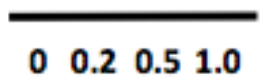 \\ Calpain

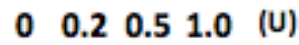

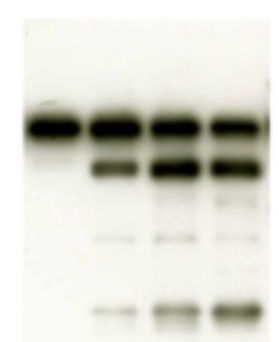

Figure 1: Using the recombinant Hsp70.1 proteins (200 ng) and the thalamus tissue $(20 \mu \mathrm{g})$, optimal concentration of purified $\mu$-calpain necessary for Hsp70.1 cleavage (70 kDa to $30 \mathrm{kDa}$ ) was estimated to be 0.5 units $(U)$. Activated $\mu$-calpain alone can cleave Hsp70.1 in the absence of HNE. 
cleaved the recombinant a little bit at the HNE concentrations of 1 and $2 \mathrm{mM}$ after incubation for 2 hours. In contrast, Hsp70.1 in the thalamus tissue $(20 \mu \mathrm{g})$ was cleaved sufficiently by $3 \mathrm{mM}$ $\mathrm{Ca}^{2+}$ regardless of the HNE concentration. Accordingly, $3 \mathrm{mM} \mathrm{Ca}^{2+}$ was utilized in the following experiments. Although the Hsp70.1 cleavage occurred in the absence of HNE, it increased gradually after incubation with $0.5,1$ and $2 \mathrm{mM}$ of HNE (Figure 2).

Since $3 \mathrm{mM} \mathrm{Ca}^{2+}$ induced sufficient Hsp70.1 cleavage in the thalamus tissues $(20 \mu \mathrm{g})$, effect of $1 \mathrm{mM} \mathrm{Ca}^{2+}$ was studied, but the cleavage was very little (Figure 3). So, under $3 \mathrm{mM} \mathrm{Ca}^{2+}$ concentration, the effects of HNE concentrations of $0.5,1$ and 2 $\mathrm{mM}$ were analysed after incubation for 2 hours. A remarkable Hsp70.1 cleavage into $\sim 30 \mathrm{kDa}$ fragments was seen dosedependently (Figure 3). As the HNE concentration of $2 \mathrm{mM}$ was thought to be sufficient, $2 \mathrm{mM}$ HNE was utilized thereafter.

To clarify whether HNE is indispensable for the Hsp70.1 cleavage,the thalamus tissue $(20 \mu \mathrm{g})$ was incubated for 2 hours with $0.5,1$ and $2 \mathrm{mM} \mathrm{HNE}$ with or without $0.5 \mathrm{U} \mu$-calpain plus $3 \mathrm{mM} \mathrm{Ca}^{2+}$. Even in the absence of HNE, activated $\mu$-calpain could cleave Hsp70.1 into $30 \mathrm{kDa}$ fragment. In contrast, in any concentrations HNE alone could not cleave Hsp70.1 at all (Figure. 4). This indicated that HNE is not an indispensable factor for the Hsp70.1 cleavage.

Subsequently, to compare the susceptibility of Hsp70.1 to activated $\mu$-calpain, CA1, thalamus, putamen, and medulla oblongata (in all 4 samples, a smaller amount of $5 \mu \mathrm{g}$ tissues were utilized for the precise comparison of cleaved band intensities) were incubated with $2 \mathrm{mM} \mathrm{HNE}$ for 1 120 min under $3 \mathrm{mM}$ $\mathrm{Ca}^{2+}$ concentration plus $0.5 \mathrm{U} \mu$-calpain. First, the most ischemiavulnerable CA1 $(5 \mu \mathrm{g})$ was studied with the recombinant Hsp70.1 protein (200 ng) as a positive control. Although the calpain-

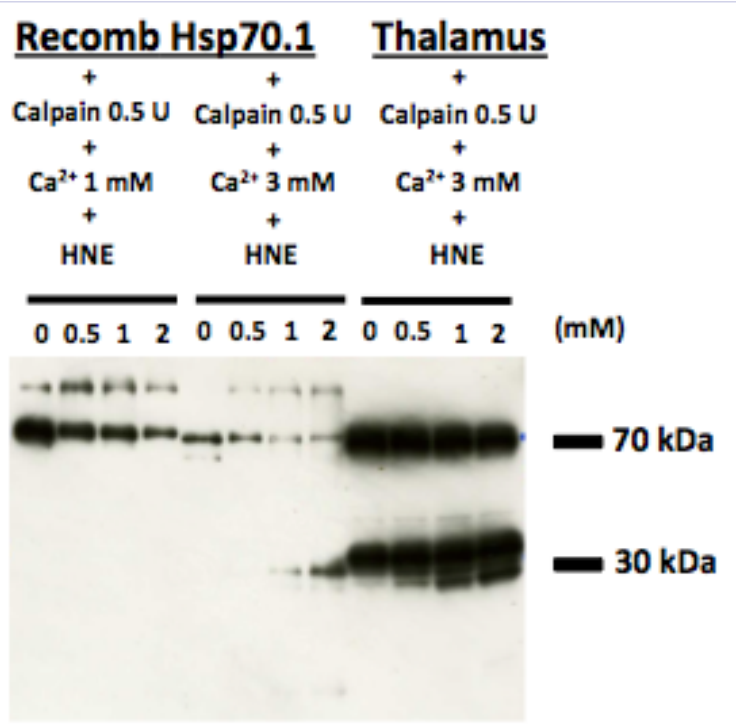

Figure 2: Using the recombinant Hsp70.1 proteins (200 ng) and the thalamus tissue $(20 \mu \mathrm{g})$, optimal concentration of $\mathrm{Ca}^{2+}$ necessary for Hsp70.1 cleavage was estimated to be $3 \mathrm{mM}$ in the present experimental paradigm.

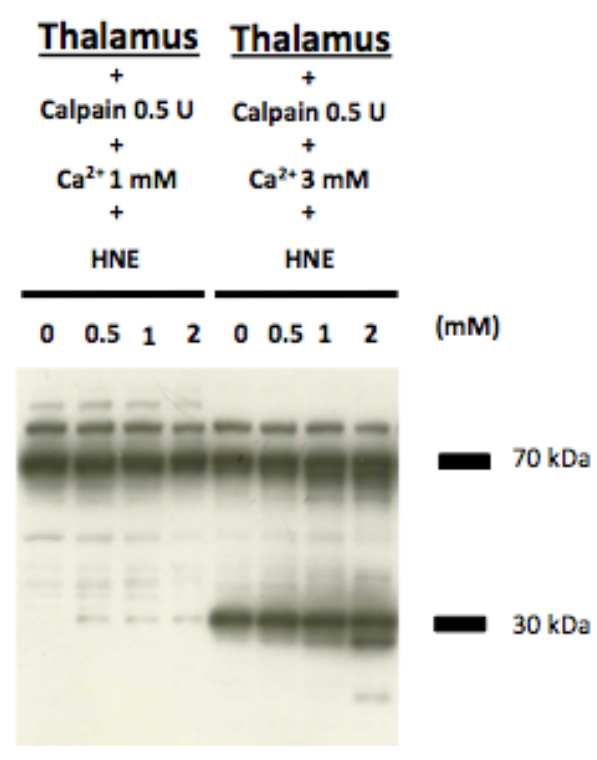

Figure 3: Using the thalamus tissues $(20 \mu \mathrm{g})$, optimal concentration of hydroxynonenal (HNE) necessary for Hsp70.1 cleavage was estimated to be $2 \mathrm{mM}$.

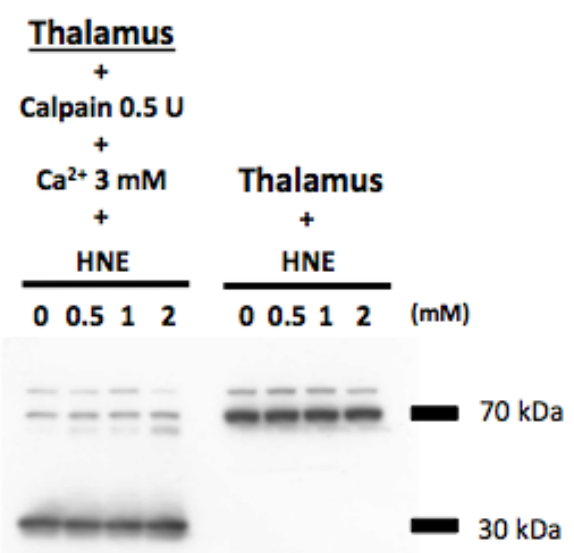

Figure 4: The thalamus tissue $(20 \mu \mathrm{g})$ showed Hsp70.1 cleavage after incubation with $0.5 \mathrm{U}$ calpain and $3 \mathrm{mM} \mathrm{Ca}^{2+}$, but $\mathrm{HNE}$ without calpain and $\mathrm{Ca}^{2+}$ showed no cleavage. Accordingly, HNE was thought to be merely an accelerator of the calpain-mediated Hsp70.1 cleavage.

mediated Hsp70.1 cleavage was negligible before HNE treatment in both the recombinant Hsp70.1 protein and CA1, the cleaved band appeared a little bit 5 min after incubation and gradually increased time-dependently (Figure 5). Using thalamus (5 $\mu \mathrm{g}$ ) (Figure 6) and medulla oblongata $(5 \mu \mathrm{g})$ (Figure 7), similar cleavage was shown to occur time-dependently after incubation with $2 \mathrm{mM}$ HNE for 1 120 min under $3 \mathrm{mM} \mathrm{Ca}^{2+}$ concentration plus $0.5 \mathrm{U} \mu$-calpain. The same results were obtained using globes pallidus and caudate nucleus (data not shown).

Finally, the cleaved band intensities of the four brain tissues (precisely $5 \mu \mathrm{g}$ for each) were compared within the same gel electrophoresis after incubation with $2 \mathrm{mM} \mathrm{HNE}$ at 10 and 30 


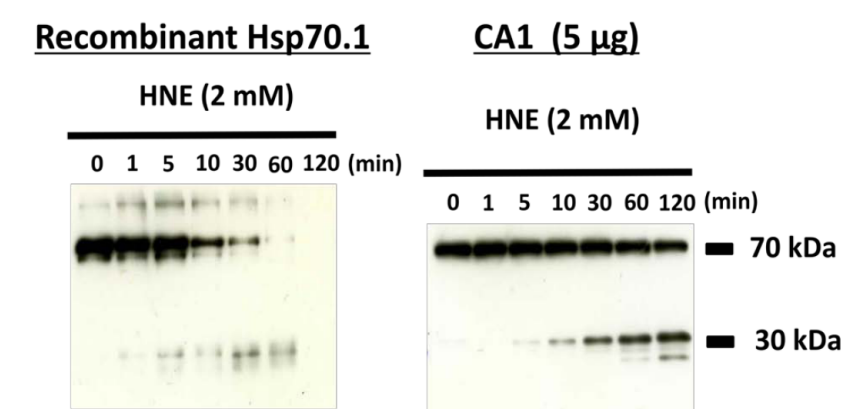

Figure 5: Calpain-mediated Hsp70.1 cleavage occurs time-dependently in both the CA1 tissue $(5 \mu \mathrm{g})$ and the recombinant Hsp70.1 protein $(200$ ng) after incubation with $3 \mathrm{mM} \mathrm{Ca}^{2+}$ and $2 \mathrm{mM} \mathrm{HNE}$.

\section{Thalamus}

HNE (2 mM)

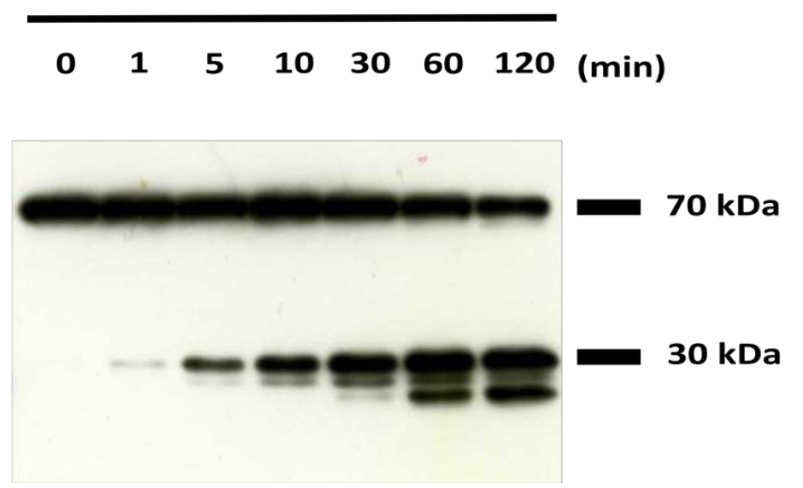

Figure 6: Calpain-mediated Hsp70.1 cleavage occurs time-dependently in the thalamus tissue $(5 \mu \mathrm{g})$ after incubation with $3 \mathrm{mM} \mathrm{Ca}^{2+}$ and $2 \mathrm{mM}$ HNE.

\section{Medulla oblongata}

\section{HNE (2 mM)}

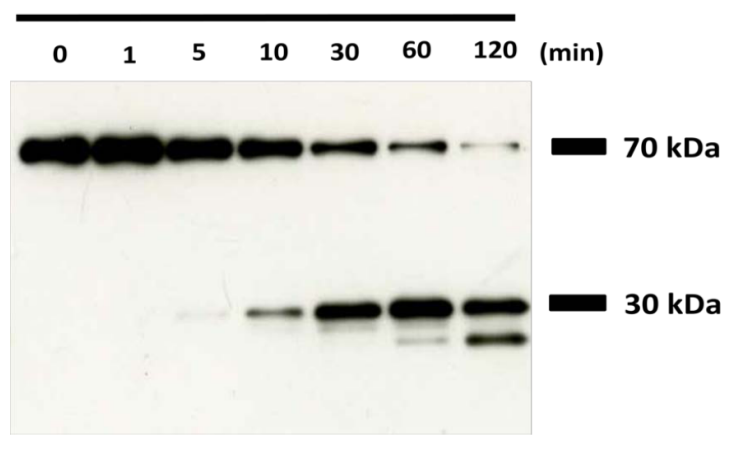

Figure 7: Calpain-mediated Hsp70.1 cleavage occurs time-dependently in the medulla oblongata tissue $(5 \mu \mathrm{g})$ after incubation with $3 \mathrm{mM} \mathrm{Ca}^{2+}$ and $2 \mathrm{mM}$ HNE.

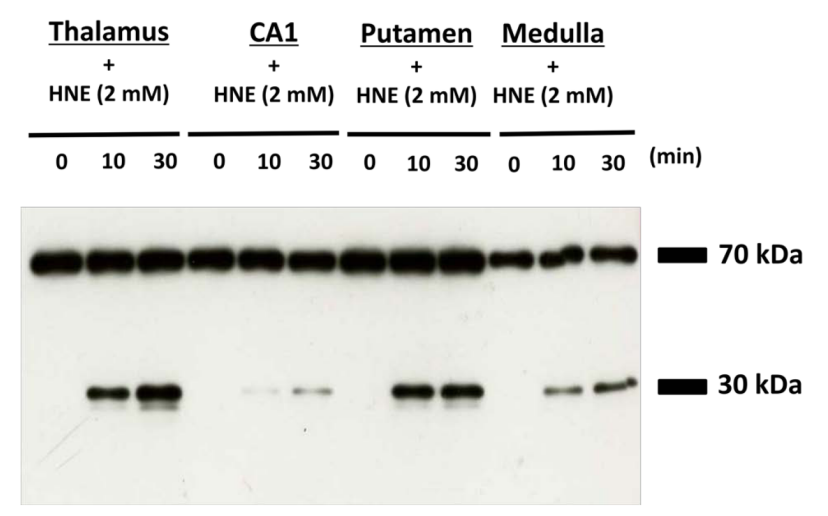

Figure 8: Comparison of calpain-mediated Hsp70.1 cleavage after incubation with $3 \mathrm{mM} \mathrm{Ca}^{2+}$ and $2 \mathrm{mM} \mathrm{HNE}$ among 4 tissues; thalamus, CA1, putamen and medulla oblongata (each $5 \mu \mathrm{g}$ ). Interestingly, the CA1 tissue showed the minimum cleavage among them that was confirmed by repeated Western blots.

min under $3 \mathrm{mM} \mathrm{Ca}{ }^{2+}$ concentration plus $0.5 \mathrm{U} \mu$-calpain. The Hsp70.1 cleavage was maximum in thalamus or putamen, but surprisingly it was minimum in CA1 (Fig. 8). Although the CA1 tissues from the different monkeys were studied repeatedly, the results were the same.

\section{Discussion}

Because of the presence of numerous dendrites and very long axon, neurons must maintain considerably large volumes of membrane and cytoplasm, and continually traffic autophagyrelated substrates long distances back to the cell body where lysosomes are most active for degradation [24]. Protein quality control, done by a balance between its folding and degradation, is fundamental to the cell homeostasis. Together with optimal co-chaperones, Hsp70.1 recognizes irreversibly aged/damaged proteins and ubiquitinates these proteins, thereby targeting them for degradation via proteasomes. Further, it recognizes proteins containing the marker sequence KFPRQ and sends them for degradation into lysosomes [25]. Hsp70.1 is crucial not only as a molecular chaperone but also as a stabilizer of the limiting membrane. It contributes to lysosomal stabilization by binding to the anionic phospholipid, Bis(Monoacylglycero) Phosphate (BMP), a co-factor essential for sphingomyelin metabolism [4]. Hsp70.1-BMP binding enhances activity of acid sphingomyelinase, which mediates the sphingolipid degradation at the internal membrane in the acidic $(\mathrm{pH} 4.5)$ compartment to generate ceramide [26-28]. Ceramide protects the lysosomal limiting membrane from rupturing [4,29,30], presumably because the increased concentration of lysosomal ceramide can facilitate fusion of lysosomes with other intracellular vesicles and membranes, and strengthen limiting membranes [31].

Lipid peroxidation is the oxidative deterioration of polyunsaturated fatty acids containing two or more carboncarbon $(\mathrm{C}=\mathrm{C}$ ) double bonds. Following lipid peroxidation, HNE and malondialdehyde are the most abundant aldehydes produced, while acrolein is the most reactive $[18,32,33]$. HNE is a 9-carbon amphiphilic lipid with both water-soluble and lipophilic 
properties that make it remain associated with the membranes [19]. Thus, HNE-membrane interaction provides a reactivity of HNE with proteins inside and outside the cell [33]. HNE forms adducts with four different side chains in proteins, namely Cys, His, Lys, and Arg. Cys residues displayed by far the highest reactivity, and the order of the molar HNE/amino acid ratio was Cys $(0.6)>>$ His $\left(1 \times 10^{-3}\right)>$ Lys $\left(3 \times 10^{-4}\right)>>\operatorname{Arg}\left(4 \times 10^{-5}\right)$ [34]. Accordingly, numerous proteins are modified by HNE, including plasma membrane ion and nutrient transporters; receptors for growth factors and neurotransmitters; mitochondrial electron transport chain proteins; protein chaperones; proteasomal proteins; and cytoskeletal proteins [35,36].

Uncontrolled and/or excessive production of HNE interferes with normal cellular signaling and disrupts ion homeostasis such as $\mathrm{Ca}^{2+}$, impairs $\mathrm{Na}^{+} / \mathrm{K}^{+}$ATPase activity, disrupts the microtubule structure, and activates the caspase pathways. A recent review of Perluigi, et al. [32] described the role of lipid peroxidation, particularly of HNE-induced protein modification in neurodegenerative diseases. HNE is a potent modulator of numerous cell processes such as oxidative stress signaling, cell proliferation, transformation, or cell death. Although the effects of HNE have been a focus of the recent research, the detailed mechanism of its effects upon neuronal death had been unknown. Interestingly, however, two-dimensional carbonyl immunoblots of the postischemic monkey hippocampal tissues after immunoprecipitation with anti-Hsp70.1 antibody, showed a remarkable upregulation of carbonylated Hsp70.1. A decrease of its molecular weight from 157.20 to 113.12 indicated oxidative injury of Hsp70.1 [11]. Accordingly, we suggested that 'HNE-induced Hsp70.1 carbonylation' may be a crucial event for elucidating the mechanism of neuronal death $[11,12]$, but whether and how HNE increases the risk of neuronal death have been incompletely understood.

Calpain is $\mathrm{Ca}^{2+}$-regulated cysteine protease, playing an important role in the regulation of cell death [22]. The 'calpaincathepsin hypothesis' corroborated the role of lysosomal rupture as an executor of programmed neuronal necrosis after transient brain ischemia in the non-human primates [12,14,37-44]. During ischemia, excessive $\mathrm{Ca}^{2+}$ mobilization occurs specifically in the CA1 neuron, and $\mu$-calpain is remarkably activated. During reperfusion, oxidation of $\omega-6$ polyunsaturated fatty acids by ROS produces HNE which carbonylates Hsp70.1 at the lysosomal membrane. Then, carbonylated Hsp70.1 is efficiently cleaved by activated $\mu$-calpain, and this leads to the lysosomal membrane destabilization/rupture. Since calpain was found to be activated at the lysosomal membranes [38,41], both calpain activation and Hsp70.1 carbonylation may occur at the same place simultaneously. Consequently, release of hydrolytic enzyme cathepsins from the lysosomal lumen occurs to induce programmed CA1 neuronal necrosis within the CA1 sector [12]. Since the in-vitro Hsp70.1 cleavage was blocked by a calpain inhibitor N-Acetyl-Leu-Leu-Nle-CHO (ALLN) dose-dependently, it is likely that Hsp70.1 can be more efficiently cleaved by activated $\mu$-calpain especially after HNE-induced carbonylation [23,43,44].

Neurons are highly sensitive to ROS, because it contains the highest content of polyunsaturated fatty acids among the body. ROS can attack linoleic and arachidonic acids incorporated into the brain to generate HNE. Toxic properties of HNE have been extensively demonstrated for various neurodegenerative diseases, however, the detailed mechanisms of HNE neurotoxicity was suggested very recently $[13,43,44]$. As mentioned above, two events of calpain activation and HNE generation contribute to the lysosomal destabilization/rupture. In this study, activated $\mu$-calpain alone could cleave Hsp70.1 whereas HNE alone failed to cleave Hsp70.1. Accordingly, it is conceivable that calpain is the principal factor while HNE is the supportive factor for Hsp70.1 cleavage leading to neuronal death. With the aid of HNE, activated $\mu$-calpain would facilitate lysosomal destabilization by cleaving carobonylated Hsp70.1 sufficiently. In addition, under the same level of $\mathrm{Ca}^{2+}$ mobilization, the more the intake of $\omega=$ 6 polyunsaturated fatty acids and/or the oxidative stresses, the more the Hsp70.1 cleavage may occur in proportion to the amount of HNE generated.

Hippocampal CA1 is well known to be extremely vulnerable to the ischemic insult. After the transient ischemia, CA1 neurons develop cell death on days 5 7 after ischemia [40]. However, the present data intriguingly showed that calpain-mediated cleavage of carbonylated Hsp70.1 occurred much less in the CA1 tissues, compared to thalamus, putamen, and medulla oblongata. Accordingly, it is suggested that calpain is a principal factor while HNE is a supportive factor for Hsp70.1 cleavage. As calpain is $\mathrm{Ca}^{2+}$-dependent, processes involving the management of intracellular $\mathrm{Ca}^{2+}$ can influence the extent and length of calpain activation and mainly determine the cell death fate. Since the CA1 slice showed the greatest $\mathrm{Ca}^{2+}$ mobilization during hypoxiahypoglycemia [37], excessive calpain activation may occur most remarkably there, and this can explain the specific vulnerability of CA1 neurons. Maintenance of $\mathrm{Ca}^{2+}$ homeostasis is critical for neuronal viability; however, tight regulation of its intracellular concentrations would be disturbed during ischemia especially in the vulnerable neurons. As the increasing HNE generation can cause a stepwise escalation in Hsp70.1 cleavage, the subjects with decreased cerebral blood flow due to arteriosclerosis and potential calpain activation had better avoid intake of excessive $\omega$ $=6$ polyunsaturated fatty acids (for example, cheap cooking oils or everything made from it - mayonnaise, margarine, dressing and deep-fried dishes).

In summary, the authors here provided direct evidence by the cleavage assay in vitro that Hsp70.1 protein in the various brain regions is the substrate of cysteine protease $\mu$-calpain, and that calpain-mediated cleavage of oxidized Hsp70.1 causes neurodegeneration in response to the abnormal $\mathrm{Ca}^{2+}$ mobilization and HNE accumulation. We speculate that under the stress condition, for example brain ischemia, the cleavage of Hsp70.1 protein similary occurs anywhere in the brain, but occurs differently in response to the extent of $\mathrm{Ca}^{2+}$ mobilization during the stress and HNE accumulation in the corresponding brain regions. The specific vulnerability of CA1 neurons can be explained by their excessive and/or long-standing calpain 
activation $[39,41]$ due to the remarkable $\mathrm{Ca}^{2+}$ mobilization during the stress such as ischemia.

\section{References}

1. Yamashima $\mathrm{T}$, Zhao $\mathrm{L}$, Wang $\mathrm{XD}$, Tsukada $\mathrm{T}$, Tonchev $\mathrm{AB}$. Neuroprotective effects of pyridoxal phosphate and pyridoxal against ischemia in monkeys. Nutr Neurosci. 2001;4(5):389-97.

2. Syntichaki P, Xu K, Driscoll M, Tavernarakis N. Specific aspartyl and calpain proteases are required for neurodegeneration in C. elegans. Nature. 2002;419: 939-44. doi:10.1038/nature01108.

3. Kirkegaard T, Jäättelä M. Lysosomal involvement in cell death and cancer. Biochim Biophys Acta. 2009;1793(4):746-54. doi: 10.1016/j. bbamcr.2008.09.008.

4. Kirkegaard T, Roth AG, Petersen NH, Mahalka AK, Olsen OD, Moilanen I, et al. Hsp70 stabilizes lysosomes and reverts Niemann-Pick disease-associated lysosomal pathology. Nature. 2010;463:549-53. doi:10.1038/nature08710.

5. Lee SH, Kwon HM, Kim YJ, Lee KM, Kim M, Yoon BW. Effects of Hsp70.1 gene knockout on the mitochondrial apoptotic pathway after focal cerebral ischemia. Stroke. 2004;35(9):2195-9. doi:10.1161/01. STR.0000136150.73891.14

6. Marber MS, Mestril R, Chi SH, Sayen MR, Yellon DM, Dillmann WH. Overexpression of the rat inducible $70-\mathrm{kD}$ heat stress protein in a transgenic mouse increases the resistance of the heart to ischemic injury. J Clin Invest. 1995;95(4):1446-56. doi: 10.1172/JCI117815.

7. Fudaba Y, Tashiro H, Ohdan H, Miyata Y, Shibata S, Shintaku S, et al. Efficacy of HSP72 induction in rat liver by orally administered geranylgeranylacetone. Transpl Int. 2000;13(1):S278-81.

8. Kelly S, Bieneman A, Horsburgh K, Hughes D, Sofroniew MV McCulloch J, et al. Targeting expression of hsp70i to discrete neuronal populations using the Lmo-1 promoter: assessment of the neuro protective effects of hsp70i in vivo and in vitro. J Cereb Blood Flow Metab. 2001;21(8):972-81. doi: 10.1097/00004647-20010800000010 .

9. Matsumori Y, Hong SM, Aoyama K, Fan Y, Kayama T, Sheldon RA, et al Hsp70 overexpression sequesters AIF and reduces neonatal hypoxic/ ischemic brain injury. J Cereb Blood Flow Metab. 2005;25(7):899-910. doi: $10.1038 /$ sj.jcbfm. 9600080 .

10. Nakajima E, David LL, Bystrom C, Shearer TR, Azuma M. Calpainspecific proteolysis in primate retina: contribution of calpains in cell death. Invest Ophthalmol Vis Sci. 2006;47(12):5469-75. doi: 10.1167/ iovs.06-0567.

11. Oikawa S, Yamada T, Minohata T, Kobayashi H, Furukawa A, TadaOikawa S, et al. Proteomic identification of carbonylated proteins in the monkey hippocampus after ischemia-reperfusion. Free Radic Biol Med. 2009;46(11):1472-7. doi: 10.1016/j.freeradbiomed.2009.02.029.

12. Yamashima T, Oikawa S. The role of lysosomal rupture in neuronal death. Prog Neurobiol. 2009;89(4):343-58. doi: 10.1016/j. pneurobio.2009.09.003.

13. Carbone DL, Doorn JA, Kiebler Z, Sampey, BP, Petersen DR. Inhibition of Hsp72-mediated protein refolding by 4-hydroxy-2-nonenal. Chem Res Toxicol. 2004;17(11):1459-67. doi: 10.1021/tx049838g.

14.Zhu H, Yoshimoto T, Yamashima T. Heat Shock protein 70.1 (Hsp70.1) affects neuronal cell fate by regulating lysosomal acid sphingomyelinase. J Biol Chem. 2014;289(40):27432-43. doi: 10.1074/jbc.M114.560334.
15. Koriyama Y, Sugitani K, Ogai K, Kato S. Heat shock. protein 70 induction by valproic acid delays photoreceptor cell death by N-methyl-N-nitrosourea in mice. J Neurochem. 2014;130(5):707-19. doi: $10.1111 /$ jnc. 12750 .

16. VanWinkle WB, Snuggs M, Miller JC, Buja LM. Cytoskeletal alterations in cultured cardiomyocytes following exposure to the lipid peroxidation product, 4-hydroxynonenal. Cell Motil Cytoskeleton. 1994;28(2):11934. doi: $10.1002 / \mathrm{cm} .970280204$.

17. Chaudhary P, Sharma R, Sharma A, Vatsyayan R, Yadav S, Singhal SS, et al. Mechanisms of 4-hydroxy-2-nonenal induced pro- and anti-apoptotic signaling. Biochemistry. 2010;49(29):6263-75. doi: 10.1021/bi100517x.

18. Dalleau S, Baradat M, Guéraud F, Huc L. Cell death and diseases related to oxidative stress: 4-hydroxynonenal (HNE) in the balance. Cell Death Differ. 2013;20(12):1615-30. doi: 10.1038/cdd.2013.138.

19. Mattson MP. Roles of the lipid peroxidation product 4-hydroxynonenal in obesity, the metabolic syndrome, and associated vascular and neurodegenerative disorders. Exp Gerontol. 2009;44(10):625-33. doi: 10.1016/j.exger.2009.07.003.

20. Keller JN, Pang Z, Geddes JW, Begley JG, Germeyer A, Waeg G, Mattson MP. Impairment of glucose and glutamate transport and induction of mitochondrial oxidative stress and dysfunction in synaptosomes by amyloid beta-peptide: role of the lipid peroxidation product 4-hydroxynonenal. J Neurochem. 1997;69(1):273-84.

21. Mark RJ, Lovell MA, Markesbery WR, Uchida K, Mattson MP. A role for 4-hydroxynonenal, an aldehydic product of lipid peroxidation, in disruption of ion homeostasis and neuronal death induced by amyloid beta-peptide. J Neurochem. 1997;68(1):255-64.

22. Bevers MB, Neumar RW. Mechanistic role of calpains in postischemic neurodegeneration J Cereb Blood Flow Metab. 2008;28(4):655-73. doi: $10.1038 /$ sj.jcbfm. 9600595 .

23. Sahara S, YamashimaT. Calpain-mediated Hsp70.1 cleavage in hippocampal CA1 neuronal death. Biochem Biophys Res Commun. 2010;393(4):806-11. doi: 10.1016/j.bbrc.2010.02.087.

24. Lee S, Sato Y, Nixon RA. Lysosomal proteolysis inhibition selectively disrupts axonal transport of degradative organelles and causes an Alzheimer's-like axonal dystrophy. J Neurosci. 2011;31(21):7817-30. doi: 10.1523/JNEUROSCI.6412-10.2011.

25. Malyshev I. Immunity, tumors and aging: The role of Hsp70, Springer Briefs in Biochem and Mol Biol. 2013. DOI: 10.1007/978-94-0075943-5_2.

26. Linke T, Wilkening G, Lansmann S, Moczall H, Bartelsen O, Weisgerber J, et al. Stimulation of acid sphingomyelinase activity by lysosomal lipids and sphingolipid activator proteins. Biol Chem. 2001;382(2):283-90. doi: 10.1515/BC.2001.035.

27. Linke T, Wilkening G, Sadeghlar F, Mozcall H, Bernardo K, Schuchman $\mathrm{E}$, et al. Interfacial regulation of acid ceramidase activity. Stimulation of ceramide degradation by lysosomal lipids and sphingolipid activator proteins. J Biol Chem. 2001;276(8):5760-8. doi: 10.1074/ jbc.M006846200.

28. Kolter T, Sandhoff K. Principles of lysosomal membrane digestion: stimulation of sphingolipid degradation by sphingolipid activator proteins and anionic lysosomal lipids. Annu Rev Cell Dev Biol. 2005;21:81-103. doi: 10.1146/annurev.cellbio.21.122303.120013

29. Petersen NH, Kirkegaard T. HSP70 and lysosomal storage disorders: novel therapeutic opportunities. Biochem Soc Trans. 2010;38(6):147983. doi: 10.1042/BST0381479.

30. Petersen NH, Kirkegaard T, Olsen OD, Jäättelä M. Connecting 
Hsp70, sphingolipid metabolism and lysosomal stability. Cell Cycle. 2010;9(12):2305-9. Doi:10.4161/cc.9.12.12052.

31. Heinrich M, Wickel M, Winoto-Morbach S, Schneider-Brachert W, Weber T, Brunner J, et al. Ceramide as an activator lipid of cathepsin D. Adv Exp Med Biol. 2000;477:305-15. doi: 10.1007/0-306-468263_33.

32.Perluigi M, Coccia R, Butterfield DA. 4-hydroxy-2-nonenal, a reactive product of lipid peroxidation, and neurodegenerative diseases: A toxic combination illuminated by redox proteomics studies. Antioxid Redox Signal. 2012;17(11):1590-609. doi: 10.1089/ars.2011.4406.

33. Schaur RJ, Siems W, Bresgen N, Eckl PM. 4-Hydroxy-nonenal-A bioactive lipid peroxidation product. Biomolecules. 2015;5(4):2247337. doi: 10.3390/biom5042247.

34. Legards JF, des Rosiers C. 16-18 June 2006. Assay of 4-hydroxynonenal (HNE) adducts with various polyaminoacids (PAA) using gas chromatography-mass spectrometry (GCMS). In Proceedings of the 3rd International Meeting of the HNE-Club, Genova, Italy.

35. Petersen DR, Doorn JA. Reactions of 4-hydroxynonenal with proteins and cellular targets. Free Radic Biol Med. 2004;37(7):937-45. doi: 10.1016/j.freeradbiomed.2004.06.012.

36. Poli G, Biasi F, Leonarduzzi G. 4-hydroxynonenal-protein adducts: A reliable biomarker of lipid oxidation in liver diseases. Mol Aspects Med. 2008;29(1-2):67-71. DOI: 10.1016/j.mam.2007.09.016.

37. Yamashima T, Saido TC, Takita M, Miyazawa A, Yamano J, Miyakawa $\mathrm{A}$, et al. Transient brain ischaemia provokes $\mathrm{Ca}^{2+}, \mathrm{PIP}_{2}$ and calpain responses prior to delayed neuronal death in monkeys. Eur J Neurosci. 1996;8(9):1932-44.

38. Yamashima T, Kohda Y, Tsuchiya K, Ueno T, Yamashita J, Yoshioka $\mathrm{T}$, et al. Inhibition of ischaemic hippocampal neuronal death in primates with cathepsin B inhibitor CA-074: a novel strategy for neuroprotection based on 'calpain-cathepsin hypothesis'. Eur J Neurosci. 1998;10(5):1723-33.

39. Yamashima $T$, Tonchev $A B$, Tsukada $T$, Saido $T C$, Imajoh-Ohmi $\mathrm{S}$, Momoi $\mathrm{T}$, et al. Sustained calpain activation associated with lysosomal rupture executes necrosis of the postischemic CA1 neurons in primates. Hippocampus. 2003;13(7):791-800. doi: 10.1002/ hipo.10127.

40. Yamashima T. Implication of cysteine proteases calpain, cathepsin and caspase in ischemic neuronal death of primates. Prog Neurobiol. 2000;62(3):273-95.

41. Yamashima T. $\mathrm{Ca}^{2+}$-dependent proteases in ischemic neuronal death: a conserved 'calpain-cathepsin cascade' from nematodes to primates. Cell Calcium. 2004;36(3-4):285-93. doi: 10.1016/j.ceca.2004.03.001.

42.Yamashima T. Hsp70.1 and related lysosomal factors for necrotic neuronal death. J Neurochem. 2012;120(4):477-94. doi: 10.1111/ j.1471-4159.2011.07596.

43.Yamashima T. Reconsider Alzheimer's disease by the 'calpaincathepsin hypothesis'--a perspective review. Prog Neurobiol. 2013;105:1-23. doi: 10.1016/j.pneurobio.2013.02.004. 